\title{
Diversity of feeding strategies in loggerhead sea turtles from the Cape Verde archipelago
}

\author{
Sahmorie J. K. Cameron ${ }^{1}$ (D) Miguel Baltazar-Soares ${ }^{2} \cdot$ Victor A. Stiebens $^{1,3} \cdot$ Thomas Reischig $^{4} \cdot$ Sandra M. Correia ${ }^{5}$. \\ Chris Harrod $^{6,7} \cdot$ Christophe Eizaguirre $^{1}$
}

Received: 30 October 2018 / Accepted: 17 August 2019 / Published online: 18 September 2019

(c) The Author(s) 2019

\begin{abstract}
As biodiversity worldwide is decreasing, to preserve adaptive potential, the importance of maintaining species' genetic and trait diversities is increasing. An efficient foraging strategy is a critical trait for an organism's fitness, as it affects its physiology and reproduction. Understanding such strategies is especially relevant for species with long feeding migrations such as sea turtles. Using carbon and nitrogen stable isotopes combined with mitochondrial sequencing, we explored the diversity of feeding strategies in genetically differentiated nesting groups of loggerhead sea turtles (Caretta caretta) within the Cape Verde Archipelago. Here, we reveal a pattern where turtles from most islands use two distinct oceanic feeding strategies, including one putatively linked to a ${ }^{15} \mathrm{~N}$-enriched zone of the West African upwelling area. On the Eastern island of Boavista, an additional third strategy exists used by turtles feeding mostly neritically. Contrary to previous paradoxical assumptions, oceanic turtles, that represent the vast majority of the population, are not smaller than neritic turtles and therefore do not seem to feed in a suboptimal environment. Our results also suggest that the number of feeding strategies may correlate with demography, whereby a greater feeding strategy diversity matches demographic signs of recent expansion after a population bottleneck for turtles nesting on the island of Boavista. Overall, the feeding ecology of Cape Verde loggerhead turtles is complex and likely shaped by an interaction between environmental and population parameters. Our results stress the importance of conservation efforts to prevent loss of critical diversity in endangered species.
\end{abstract}

Responsible Editor: J. Raeymaekers.

Reviewers: Undisclosed experts.

Electronic supplementary material The online version of this article (https://doi.org/10.1007/s00227-019-3571-8) contains supplementary material, which is available to authorized users.

Sahmorie J. K. Cameron

s.j.k.cameron@qmul.ac.uk

$\checkmark$ Christophe Eizaguirre

c.eizaguirre@qmul.ac.uk

Miguel Baltazar-Soares

mbaltazarsoares@bournemouth.ac.uk

Victor A. Stiebens

victorstiebens@gmail.com

Thomas Reischig

reischig@turtle-foundation.org

Sandra M. Correia

Sandra.Correia@indp.gov.cv

Chris Harrod

Chris@harrodlab.net

\section{Introduction}

As the number of extant species continues to fall at an unprecedented rate (Pimm et al. 2014), the importance of preserving diversity worldwide has never been higher, whether to protect species' genetic diversity, traits, or

1 School of Biological and Chemical Sciences, Queen Mary University of London, Mile End Road, London E1 4NS, UK

2 Faculty of Science and Technology, Bournemouth University, Christchurch House, Talbot Campus, Poole, Dorset BH12 5BB, UK

3 Maio Biodiversity Foundation (FMB), Cidade do Porto Inglês, Maio, Cape Verde

4 Turtle Foundation, An der Eiche 7a, 50999 Cologne, Germany

5 National Institute for the Development of Fisheries (INDP), Mindelo 116, Cape Verde

6 Instituto de Ciencias Naturales Alexander von Humboldt, Universidad de Antofagasta, Avenida Angamos 601, Antofagasta, Chile

7 Núcleo Milenio INVASAL, Concepción, Chile 
behaviours (Isaac and Cowlishaw 2004; Myers et al. 2000). An efficient foraging strategy is one of the most important components for the survival and Darwinian fitness of an organism (Le Galliard et al. 2004; Stephens and Krebs 1986). The evolution of foraging strategies is the result of various selective pressures to maximize resource acquisition for growth, maintenance, or reproduction as well as to reduce encounters with predators (Börger et al. 2008; Sims et al. 2008; Stephens and Krebs 1986). Optimal feeding strategies are therefore likely to be habitat or location specific.

Several species have evolved different feeding strategies which may be linked to their jaw or beak morphology (e.g., Abzhanov et al. 2004; Albertson et al. 2005) but also to their size, allowing them to access specific food items (e.g., Hawkes et al. 2006). Understanding the origin of traits underlying feeding strategies, as well as their variation, can offer unique insights into the ecology of organisms and help maintain their adaptive potential for improved conservation measures (Eizaguirre and BaltazarSoares 2014).

Stable isotopes have become important tools for conservation biologists. Particularly, carbon $\left(\mathrm{C}, \delta^{13} \mathrm{C}\right)$ and nitrogen $\left(\mathrm{N}, \delta^{15} \mathrm{~N}\right)$ provide information on the specific habitats used by the target species as well as on their trophic position and the source of primary production (Hobson 1999; Post 2002; Reich et al. 2007). Relatively slow turnover of isotopes in certain tissues also means that migrating consumers continue to exhibit stable isotope values representative of their feeding grounds even after leaving them. This characteristic makes $\delta^{13} \mathrm{C}$ and $\delta^{15} \mathrm{~N}$ excellent markers to identify the presence of various feeding strategies in a population of migrating and difficult to access organisms.

Sea turtles are prime examples of marine species whose migrations to and from feeding grounds can span thousands of kilometres (Godley et al. 2008; Hawkes et al. 2006) or entire ocean basins (Bolten and Witherington 2003). Adult female sea turtles are capital breeders and, as such, spend most of their time gaining energy for reproduction at their feeding grounds, only returning to their natal area every so often to breed and lay eggs (Plotkin 2003; Stearns 1992; Zbinden et al. 2011). During the nesting period, female turtles are accessible for sampling on land with minimal stress imposed on them.

The loggerhead sea turtle (Caretta caretta) represents the most abundant sea turtle species in warm temperate regions (Bolten and Witherington 2003; Dodd 1988; Eder et al. 2012). At a global level, its population size is low despite a recent upgrade on the IUCN Red List from 'Endangered' to 'Vulnerable'. The species is, however, still classified as "Endangered" (Cape Verde) and even "Critically Endangered" (North Indian Ocean \& South Pacific) in certain other rookeries (IUCN 2016).
Recent stable isotope studies, bolstered by improved satellite tracking technology, have allowed monitoring of loggerhead turtles throughout their feeding migrations. Numerous studies report a dichotomy of foraging strategies with individuals of the same population following either an oceanic or neritic feeding strategy (Cape Verde RookeryEder et al. 2012; Hawkes et al. 2006, East USA RookeryMcClellan et al. 2010; McClellan and Read 2007; Japanese Rookery-Hatase et al. 2002, 2007). Oceanic individuals feed epipelagically and opportunistically on neustonic organisms, e.g., jellyfish or crustaceans (Frick et al. 2009). Neritic individuals feed upon benthic prey items such as gastropods and other slow-moving and/or sessile organisms (Frick et al. 2009; Hopkins-Murphy et al. 2003; Plotkin 2003), along with pelagic prey inhabiting coastal habitats such as jellyfish (McClellan et al. 2010; Wallace et al. 2009).

Due to the abundance of nutrient-rich benthic fauna in neritic feeding sites compared to those in often low productivity oceanic habitats, neritic turtles are thought to be larger than their oceanic counterparts (Cape Verde Rookery-Eder et al. 2012; Hawkes et al. 2006; Japanese Rookery-Hatase et al. 2002, 2007; Hatase and Tsukamoto 2008, Western Australian Rookery-Thomson et al. 2012). Whilst this prediction seems to hold in the Northwest Atlantic, Japanese and central Mediterranean populations (Hatase et al. 2010; Hawkes et al. 2011; Zbinden et al. 2011), most individuals sampled from the Cape Verde archipelago and Oman are oceanic foragers (Cape Verde =e.g. 87.5\%, Eder et al. 2012; Oman $=80 \%$, Rees et al. 2010). This reveals an evolutionary paradox whereby most of the turtles from those rookeries may be using an a priori suboptimal feeding strategy that is assumed to be heritable, which raises the question about how such a behaviour has evolved and is maintained (Smith and Price. 1973).

The Cape Verde archipelago consists of ten volcanic islands (Fig. 1), located approximately $570 \mathrm{~km}$ off the West coast of Africa in the North Atlantic Ocean. The archipelago sustains the third largest aggregation of loggerhead turtles on the planet (after Florida and Oman, Marco et al. 2012). There, turtles are classified as "Endangered" (IUCN 2016), due to traditional poaching, fisheries bycatch and coastal development (López-Jurado et al. 2003; Taylor and Cozens 2010). While the majority of nesting occurs on the most Eastern islands (Boavista, Sal, Maio), each island supports independent nesting groups with unique genetic diversity of conservation value (Stiebens et al. 2013a). Previous research undertaken on the island of Boavista revealed the existence of at least two distinct feeding strategies (Cardona et al. 2017; Eder et al. 2012), oceanic and neritic, with turtles smaller than $90 \mathrm{~cm}$ being oceanic, while turtles $>90 \mathrm{~cm}$ were considered neritic feeders (Eder et al. 2012). Those strategies are hence characterized by different feeding locations and different prey items. More recently, $\delta^{13} \mathrm{C}$ and $\delta^{15} \mathrm{~N}$ 


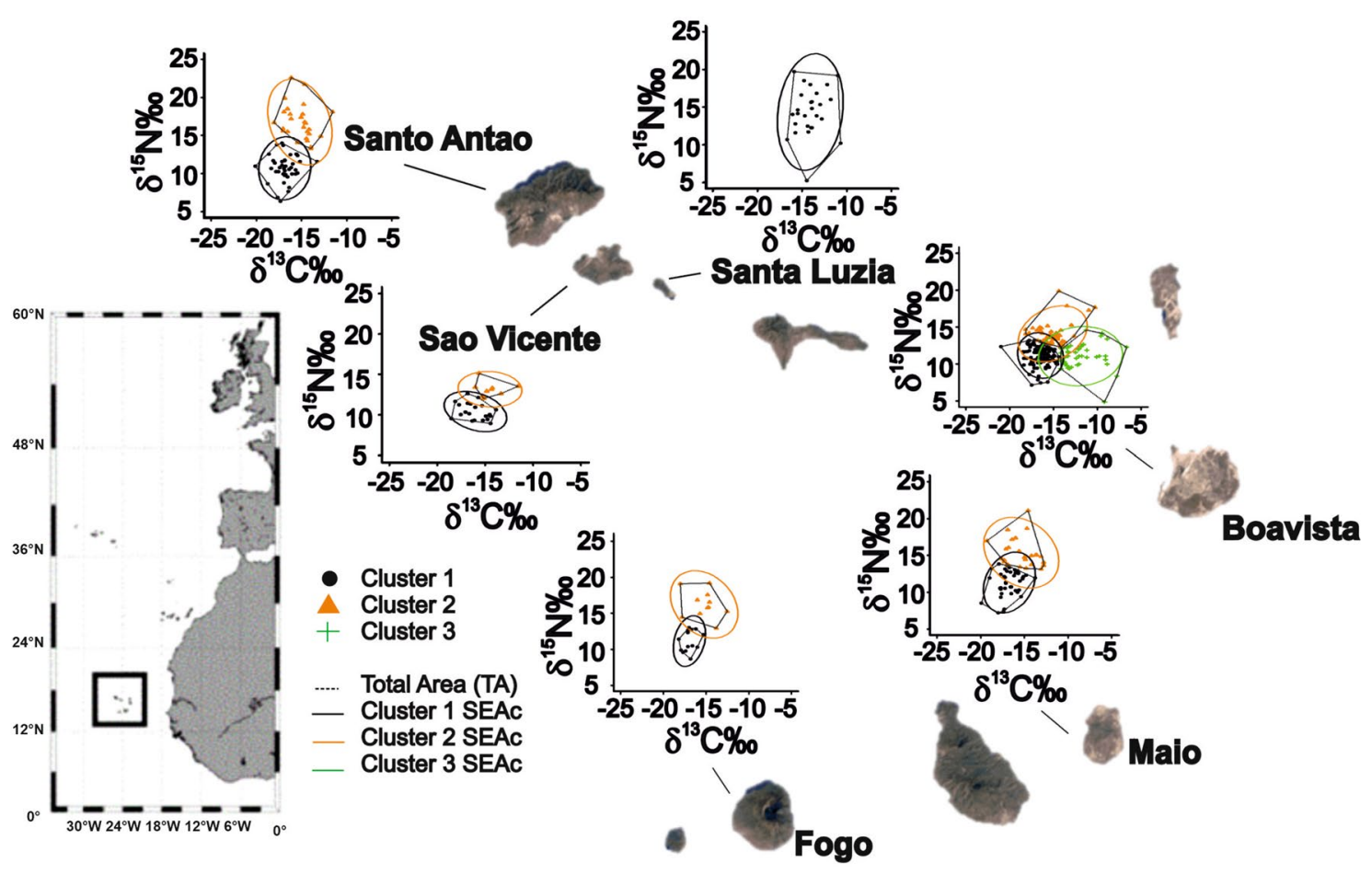

Fig. 1 Map of the Cape Verde archipelago with islands in which turtles were sampled from in this study. $\delta^{13} \mathrm{C}(\% \circ)$ and $\delta^{15} \mathrm{~N}(\% \circ)$ stable isotope biplots for each island show the total areas and standard ellip-

readings from scutes of 14 individuals showed that turtles can shift between foraging habitats (Cardona et al. 2017). Here, we determined diversity of feeding ecology in genetically distinct nesting groups using stable isotope analyses from skin tissue across the entire archipelago. We also endeavour to address the paradox of the use of suboptimal feeding strategies by the majority of turtles. We then combined this information with mitochondrial DNA sequencing to test for correlations between population demography and diversity of feeding strategies.

\section{Materials and methods}

Overall, sampling took place during the nesting seasons 2012-2014 on six different islands of the Cape Verde archipelago: Boavista, Fogo, Maio, São Vicente, Santa Luzia and Santo Antão (Fig. 1). Sampling consisted of collecting one or two pieces of $3 \mathrm{~mm}$ non-keratinized tissue from the front flippers of nesting females using a single-use sterile scalpel, immediately following egg deposition (Stiebens et al. 2013b). One was used for genetic analyses, while the other was used for stable isotopes. At that time, females were tagged with coded inconel and/or PIT (AVID) tags to avoid sampling duplication. Curved carapace length (CCL) was also measured $( \pm 0.1 \mathrm{~cm})$. ses corrected for small sample sizes, representing the isotopic niche area of each cluster

\section{Stable isotopes: preparation and readings}

We used samples from our first encounter with an individual in the nesting season to avoid possible confounding effects linked to local feeding, if it exists. We collected 419 samples, 287 of which were also sampled for mtDNA sequencing. Samples were initially washed in distilled water for approximately $1 \mathrm{~min}$ to remove sand. They were dried at $60{ }^{\circ} \mathrm{C}$ for $48 \mathrm{~h}$. Between 0.7 and $1.3 \mu \mathrm{g}$ of sample was cut and weighed into tin capsules $(4 \mathrm{~mm})$, before being combusted using a continuous flow isotope ratio mass spectrometer (Integra2, Sercon) and analysed for nitrogen and carbon elements simultaneously. Repeated run of an internal standard (casein) showed analytical error to be ca. $\pm 0.1 \%$ o for both $\mathrm{C}$ and $\mathrm{N}$.

\section{DNA sampling, and mitochondrial sequencing of the control region}

Skin samples were extracted using the DNeasy ${ }^{\circledR} 96$ Blood \& Tissue Kit (QIAGEN, Hilden, Germany) following the manufacturer's protocol except for the final elution step which was conducted in twice $75 \mu \mathrm{l}$ of AE Buffer. The long fragment (here, $750 \mathrm{bp}$ ) of control region of the mitochondrial DNA was amplified using the primers LCM15382 (5'GCTTAACCCTAAAGCATTGG-3') and H950 (5'-GTC 
TCGGATTTAGGGGTTTG-3') (Monzón-Argüello et al. 2010) following Stiebens et al. (2013a). PCR products were cleaned with ExoSAP-IT ${ }^{\circledR}$ following the manufacturer's protocol. Cycle sequencing reactions were performed with Big Dye ${ }^{\circledR}$ Terminator v3.1 Cycle Sequencing Kit (Applied Biosystems, Darmstadt, Germany). Sequences were obtained from the forward direction (primer LCM15382). Sequencing was performed with an ABI 3730 Genetic Analyzer (Applied Biosystems, Darmstadt, Germany).

\section{Data analyses}

\section{Demographic history of nesting groups}

Sequences were assembled in Codon Code Aligner v5.0 (CodonCode Corporation, Dedham, Massachusetts) and ambiguities were corrected by hand. All the amplified mitochondrial sequences were classified accordingly to the standardized nomenclature of the Archie Carr Centre for Sea Turtle Research (http://accstr.ufl.edu). The entire data set was aligned in Muscle v8.3.1 (Edgar 2004). Population structure of the archipelago was also analysed using mtDNA with Wright's fixation index $\left(F_{\mathrm{ST}}\right)$ implemented within the software Arlequin v3.5 (Excoffier and Lischer 2010). We estimated the relationship among mtDNA haplotypes throughout the archipelago using a median-joining network (Bandelt et al. 1999), with the haplotype frequencies, using Network, version 5.0.1.1 and post-processing maximum parsimony (Polzin and Daneschmand 2003). The demographic history of each nesting group was investigated using the software DNAsp (Rozas and Librado 2009), first through moment estimates of Tajima's $D$ (computed with 1000 coalescent simulations), measurement of goodness of fit, the raggedness index $r$ (Harpending et al. 1993, Harpending 1994), neutrality tests Fu's Fs (Fu 1997) and Ramos-Onsins and Rozas' $R_{2}$ (Ramos-Onsins and Rozas 2002). All were assessed for significance with 1000 coalescent simulations.

\section{Determining feeding strategies}

Statistical analyses of stable isotopes (SIA) were performed in R Studio, version 3.2.5 (The R Foundation for Statistical Computing, 2016). We classified individual turtles into putative feeding groups based on $\delta^{13} \mathrm{C}$ and $\delta^{15} \mathrm{~N}$ using affinity propagation clustering (apcluster, Bodenhofer et al. 2011). Affinity propagation relies on machine learning and, unlike $k$-means, can cluster data without pre-assuming the number of clusters. To allow different numbers of clusters to exist across nesting islands, analyses were performed within each nesting group. SIBER (Stable Isotope Bayesian Ellipses in $R$ ) was used to visualise the extent of the isotopic niche of feeding groups, identified using affinity propagation clusters, for turtles on each island. Additionally, the standard ellipse areas representing the core isotopic niche for each group, corrected for sample size (SEAc), were calculated.

Turtles were also categorised into size-related clusters where those smaller than $90 \mathrm{~cm}$ (curved carapace length, CCL) were considered a priori oceanic and those larger than $90 \mathrm{~cm}(N=26, C C L)$ were considered neritic (Eder et al. 2012; Hawkes et al. 2006; Cardona et al. 2017), independently of their SIA values. To evaluate the reliability of this grouping and test whether size really correlates with feeding ecology, linear discriminant analyses (LDA) with jackknifed classification were used to assign individuals from each island into the size-related (CCL) oceanic or neritic groups based on their $\delta^{15} \mathrm{~N}$ and $\delta^{13} \mathrm{C}$. We then tested whether size-based feeding strategies actually matched SIA-based feeding strategies-hence testing for the reliability of size as a proxy for feeding ecology.

The relationship between $\delta^{15} \mathrm{~N}$ and $\delta^{13} \mathrm{C}$ overall in all the datasets was assessed with Pearson's product moment correlation coefficient test. Independent linear mixed-effects models (lme4 and lmertest) were used to explore the relationship between CCL and isotopic cluster, as well as their interaction on $\delta^{15} \mathrm{~N}$ and $\delta^{13} \mathrm{C}$ for turtles from each nesting island. This was to test for separate vs. common slopes between the isotope values and CCL across isotope clusters. Possible variation across years was accounted for by including "year" as a random effect. Analyses had to be conducted within island, as not all detected strategies were present on all islands and therefore would bias the evaluation of the interaction between CCL and feeding strategy. Post hoc analyses were performed using multiple comparisons of means of Tukey contrast (multcomp). Furthermore, differences in CCL among isotopic clusters were assessed using independent linear mixed-effects models, with "year" as a random effect. Lastly, Pearson correlations were calculated and tested for significance to investigate possible links between the number of isotopic clusters and demographic indices (Tajima's $D$, raggedness index $r$, Fu's $F$ and $R_{2}$ ) across islands.

\section{Results}

For both SIA and mtDNA sequencing, the Eastern island of Boavista contributed a large proportion of collected samples [Electronic supplementary material (Table S1)]. This reflects the fact that most ( 60 to $70 \%$ ) nesting activity of the archipelago occurs on that island (Marco et al. 2012) and decreases in a westerly direction. Our sample sizes are therefore mostly representative of nesting densities. Overall, $\delta^{15} \mathrm{~N}$ and $\delta^{13} \mathrm{C}$ were positively correlated with one another (cor $=0.140, p=0.004$ ). 


\section{Matching isotopic clusters with feeding strategies}

The affinity propagation clustering approach revealed different numbers of clusters across different islands. On Santa Luzia, turtles were grouped into a single feeding strategy $\left(\right.$ mean $\pm \mathrm{SD} \delta^{15} \mathrm{~N}=14.4 \pm 0.6 \%$ ond $\delta^{13} \mathrm{C}=-14.1 \pm 0.3 \%$ ) corresponding to an oceanic niche. On the islands of Fogo, Maio, Santo Antão and São Vicente, we identified two isotopic clusters where all turtles had depleted ${ }^{13} \mathrm{C}$ values, also indicative of oceanic feeding strategies (Fig. 1, Table 1): $\delta^{13} \mathrm{C}$ varied between $-16.9( \pm 0.8) \%$ o in the southern island of Fogo and $-14.5( \pm 1.5) \%$ for turtles nesting on São Vicente. In the oceanic isotopic cluster $1, \delta^{15} \mathrm{~N}$ varied between $10.5( \pm 1.0) \%$ for turtles on the island of São Vicente and $11.3( \pm 2.4) \%$ o for those on the island of Maio. This pattern contrasts with the second group (isotopic cluster 2) with increased $\delta^{15} \mathrm{~N}$ values varying between 13.2 $( \pm 0.9) \%$ and $16.8( \pm 2.3) \%$ (Table 1). Overall, assuming turtles do not feed across a very large number of trophic positions, the ${ }^{15} \mathrm{~N}$-enriched values of cluster 2 turtles suggest that feeding took place in a ${ }^{15} \mathrm{~N}$-enriched area.

Turtles nesting on Boavista island were classified into three putative feeding clusters (Fig. 1, Table 1). The two oceanic clusters present on most of the other islands were detected along with a third group. This third group (cluster 3) was relatively ${ }^{15} \mathrm{~N}$-depleted (mean $\pm \mathrm{SD} \delta{ }^{15} \mathrm{~N}=11.0 \pm 1.6 \%$ ) as well as significantly ${ }^{13} \mathrm{C}$-enriched compared to the other clusters $\left(\delta^{13} \mathrm{C}=-12.0 \pm 2.0 \%\right)$ and therefore formed by turtles using a neritic feeding strategy.

\section{Clusters based on turtle size}

We evaluated whether a size-based definition of feeding strategy does match the true SIA-based feeding ecology used by turtles. To this end, we reassigned individuals into our affinity propagated isotopic clusters based on their body size (CCL, Electronic Supplementary Material, Table S2). Based on size, we could reassign correctly a maximum of $46 \%$ of the turtles on the island of Fogo and as few as 3.9\% for turtles nesting on Santa Luzia to their SIA-based feeding strategy. Even in Boavista, where previous studies have been conducted, the reassignment rate was only $20 \%$ overall, notably with only 4 (among 13 larger than $90 \mathrm{~cm}$ on that island) individuals reassigned to the neritic group in total. This ultimately demonstrates that size does not represent a sufficiently strong proxy for feeding strategy in this system.

\section{Testing for size by feeding strategy interactions}

Having determined the most likely number of feeding clusters representing distinct feeding strategies, we tested if isotope signatures change with CCL, and whether such

Table 1 Affinity propagation clusters obtained for nesting female loggerhead turtles by island based on SIA values as well as determined feeding strategy

\begin{tabular}{|c|c|c|c|c|c|c|c|c|c|}
\hline Island & $\begin{array}{l}\text { Affinity } \\
\text { propagated } \\
\text { clusters }\end{array}$ & $\begin{array}{l}\text { Number of } \\
\text { individuals per } \\
\text { cluster }\end{array}$ & $\begin{array}{l}\% \text { of individu- } \\
\text { als per cluster }\end{array}$ & Mean $\delta^{15} \mathrm{~N}(\% o)$ & SD & Mean $\delta^{13} \mathrm{C}(\% o)$ & $\mathrm{sd}$ & SEAc $(\% o)$ & Feeding strategy \\
\hline \multirow[t]{4}{*}{ Boavista } & 1 & 113 & 55.9 & 11.1 & 1.3 & -16.5 & 1.1 & 4.22 & Oceanic \\
\hline & 2 & 44 & 21.8 & 14.0 & 1.5 & -15.1 & 1.6 & 7.68 & Oceanic \\
\hline & 3 & 45 & 22.3 & 11.0 & 1.6 & -12.0 & 2.0 & 10.32 & Neritic \\
\hline & Total & 202 & & & & & & & \\
\hline \multirow[t]{3}{*}{ Fogo } & 1 & 14 & 56.0 & 11.0 & 1.4 & -16.9 & 0.8 & 3.58 & Oceanic \\
\hline & 2 & 11 & 44.0 & 16.1 & 1.9 & -15.2 & 1.6 & 10.23 & Oceanic \\
\hline & Total & 25 & & & & & & & \\
\hline \multirow[t]{3}{*}{ Maio } & 1 & 42 & 62.7 & 11.3 & 1.7 & -16.7 & 1.2 & 6.32 & Oceanic \\
\hline & 2 & 25 & 37.3 & 15.3 & 1.9 & -15.4 & 1.7 & 10.80 & Oceanic \\
\hline & Total & 67 & & & & & & & \\
\hline \multirow[t]{3}{*}{ Santo Antão } & 1 & 40 & 59.7 & 10.7 & 1.6 & -16.8 & 1.2 & 6.39 & Oceanic \\
\hline & 2 & 27 & 40.3 & 16.8 & 2.3 & -15.1 & 1.5 & 10.53 & Oceanic \\
\hline & Total & 67 & & & & & & & \\
\hline \multirow[t]{2}{*}{ Santa Luzia } & 1 & 27 & 100.0 & 14.4 & 3.2 & -14.1 & 1.5 & NA & Oceanic \\
\hline & Total & 27 & & & & & & & \\
\hline \multirow[t]{3}{*}{ São Vicente } & 1 & 22 & 71.0 & 10.5 & 1.0 & -16.1 & 1.3 & 4.22 & Oceanic \\
\hline & 2 & 9 & 29.0 & 13.2 & 0.9 & -14.5 & 1.4 & 4.38 & Oceanic \\
\hline & Total & 31 & & & & & & & \\
\hline
\end{tabular}

Standard ellipse area corrected (SEAc) for sample size for each cluster is also shown and expressed as \%o. NA appears for the island supporting only one feeding group and hence, SEAc could not be calculated 
changes were the same in each isotope cluster. Noteworthy, because turtles nesting on Santa Luzia island belong to only one feeding strategy, the analysis could not be conducted.

\section{Islands supporting turtles with two feeding strategies}

Investigating $\delta^{15} \mathrm{~N}$ variation among nesting groups (i.e., islands) consisting of two turtle isotopic clusters, no significant interaction between size (CCL) and the isotopic clusters was detected (Fogo- $F_{1 / 21}=0.367, p=0.551$, Maio- $F_{1 / 61}=1.803, p=0.184$, Santo Antão $-F_{1 / 62}=1.378$, $p=0.250$ and São Vicente $\left.-F_{1 / 8}=0.151, p=0.709\right)$. We found that cluster 2 turtles had consistently more positive ${ }^{15} \mathrm{~N}$ values than cluster 1 turtles in all islands supporting nesting groups with two feeding strategies (Fogo$F_{1 / 22}=57.922, p<0.001$, Maio $-F_{1 / 64}=64.511, p<0.001$, Santo Antão- $F_{1 / 28}=106.001, p<0.001$ and São Vicente$\left.F_{1 / 10}=27.869, p<0.001\right)$. This result indicates that cluster 2 turtles feed in highly productive environments, independent of nesting islands, suggesting that turtles with the same feeding strategies feed in similar places off the coasts of West Africa.

Turtles nesting on the island of Maio were the only ones showing an increase in $\delta^{15} \mathrm{~N}$ with individual CCL $\left(F_{1 / 62}=9.754, p=0.003\right)$. This effect was not detected for the other turtles on islands with two isotopic clusters (All $F<0.4 ; p>0.05$ ).

When investigating the factors influencing $\delta^{13} \mathrm{C}$ variation in turtles from islands with two feeding clusters, similar patterns emerged: no interaction between CCL and isotopic clusters was detected (All $F<3.2$, all $p>0.08$ ). On Maio and Santo Antão, turtles from isotopic cluster 2 showed more ${ }^{13} \mathrm{C}$-enriched values than those from cluster 1 (Maio: $F_{1 / 64}=13.398, p<0.001$, Santo Antão: $F_{1 / 63}=40.500$, $p<0.001)$. However, there was no significant difference in $\delta^{13} \mathrm{C}$ values between the two isotopic clusters on Fogo $\left(F_{1 / 24}=0.713, p=0.406\right)$ or São Vicente $\left(F_{1 / 29}=1.224\right.$, $p=0.279)$. No significant association was found between $\delta^{13} \mathrm{C}$ and CCL for turtles nesting on Maio, Fogo, Santo Antão or São Vicente (All $F<3.9, p>0.05$ ). Lastly, for the island of São Vicente, we found cluster 2 turtles to have a larger CCL than cluster 1 (Mean \pm SD CCL: Cluster $1-82.2 \pm 4.6 \mathrm{~cm}$, Cluster $2-84.8 \pm 4.0 \mathrm{~cm} ; F_{1 / 27}=5.524$, $p=0.026)$. However, no difference in CCL existed between the two clusters on the other islands supporting turtles with two feeding strategies (Cluster $1-82.7 \pm 4.9$, Cluster $2-81.8 \pm 3.3$, All $F<2.6$; All $p>0.05$ ).

\section{Island supporting turtles with three feeding strategies}

Investigating the factors driving $\delta^{15} \mathrm{~N}$ variation in turtles nesting on Boavista, where three strategies were detected, did not reveal an interaction between turtle size (CCL) and their isotopic cluster $\left(F_{1 / 194}=2.587, p=0.078\right) . \delta^{15} \mathrm{~N}$ values of group 2, the oceanic upwelling turtles, were more positive than the other isotopic groups $\left(F_{2 / 196}=71.223\right.$, $p<0.001$, all post hoc Tukey tests $p<0.01$, Fig. 2a). Additionally, no correlation was found between CCL and $\delta^{15} \mathrm{~N}$ $\left(F_{1 / 196}=1.961, p=0.163\right)$. CCL differed across isotopic clusters $\left(F_{2 / 199}=159.910, p<0.001\right)$, with turtles from oceanic upwelling areas being on average larger than individuals from oceanic cluster $1(z=2.591, p=0.026)$ and the neritic turtles ( $z=3.132, p=0.005$, Fig. 2b).

Furthermore, we found neither a change of $\delta^{13} \mathrm{C}$ with CCL nor a different relationship between $\delta^{13} \mathrm{C}$ and size in different isotopic clusters $\left(F_{3 / 277.35}=2.502, p=0.082\right)$. However, $\delta^{13} \mathrm{C}$ values in Boavista turtles varied with isotopic clusters $\left(F_{2 / 197.62}=163.637, p<0.001\right)$, with all groups

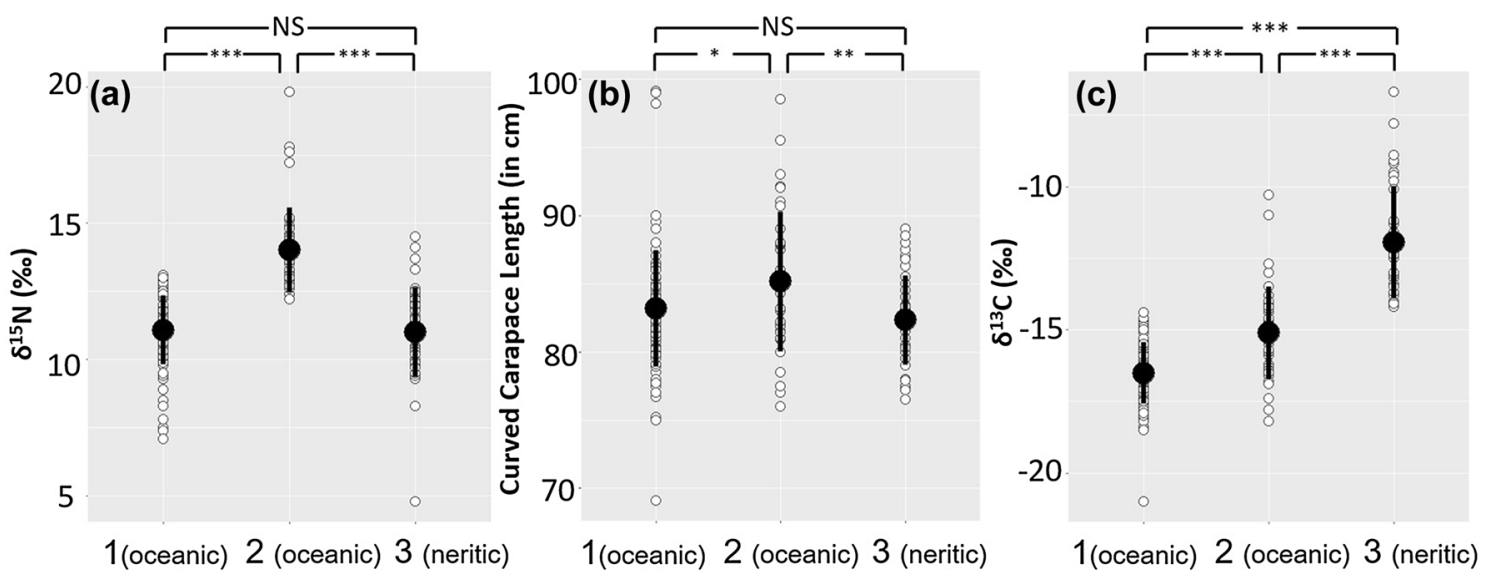

Boavista turtle isotopic cluster

Fig. 2 Plots showing the Boavista turtles isotopic cluster differences in a mean $\delta^{15} \mathrm{~N}(\% o)$ values; $\mathbf{b}$ mean curved carapace length in centimetres (CCL); and $\mathbf{c}$ mean $\delta^{13} \mathrm{C}(\%)$ values. $* P<0.05$, ** $P<0.01$, *** $P<0.001$, "NS" $-P>0.05$. Error bars represent second and third quartiles 
being significantly different from each other (all post hoc Tukey tests $p<0.010$ ). Individuals from cluster 3 , the neritic turtles, were the most ${ }^{13} \mathrm{C}$ enriched (Fig. 2c).

\section{Linking stable isotopes and demographic parameters}

We detected 17 distinct haplotypes in the mtDNA control region (Electronic Supplementary Table S3). The haplotype network mostly reflects that of the species across its entire distribution area in the Atlantic (Shamblin et al. 2014), where two haplotypes are observed (CC-A.1 and CC-A.2), with increased diversity around the CC-A.1 and CC-A17.1 haplotypes (Electronic Supplementary Figure S1, Table S3). In line with Stiebens et al. 2013a, we observed a similar genetic structure in the archipelago with the strongest genetic differentiation observed with turtles nesting on Sao Vicente and Santa Luzia islands (Electronic Supplementary Table S4). This result reinforces the view of relative independent populations being present across the archipelago (Stiebens et al. 2013a).

Analysing the control region of the mitochondrial DNA, we found that turtles nesting on the island of Boavista showed a significant negative Tajima's $D(D=-1.897$, $p=0.003$ ) suggesting a rapid expansion after a bottleneck event. On Boavista, $R_{2}$ also showed to be significant $\left(R_{2}=0.031, p=0.033\right)$. Santa Luzia turtles had a significant Fu's $F$ value (Fu's $F=-1.889, p=0.029$ ), yet this result must be taken with caution given the small sample size for this island. All demographic indices for the other islands were not significant (Electronic supplementary material, Table S1).

Lastly, we observed a weak but significant relationship between the number of feeding strategies and the raggedness index (cor $=0.815, p=0.048$ ). However, no significant relationship between the number of turtle feeding strategies and Tajima's $D$ (cor $=-0.502, p=0.311$ ), $R_{2}$ (cor $=-0.765$, $p=0.076)$ and Fu's $F(\mathrm{cor}=0.100, p=0.850)$ was found.

\section{Discussion}

Maintaining diversity, whether genetic, phenotypic or behavioural is a major goal of modern conservation biology that increasingly focuses on species' adaptive potential (Eizaguirre and Baltazar-Soares 2014). Using stable isotope analyses, we show that several feeding strategies are used by turtles nesting at the Cape Verde archipelago- the only significant nesting aggregation for loggerhead turtles in the Eastern Atlantic (Marco et al. 2012). Contrary to expectations, CCL is not revealed as a strong proxy to define a turtle's feeding strategy (illustrated in Fig. 3). With our data, we also address one of the major previous paradoxes that postulated that the vast majority of sea turtles from Cape Verde used a suboptimal feeding strategy, because oceanic turtles were thought to be smaller than their neritic counterpart. When defining feeding strategies based on stable isotopes, we did not detect this pattern, suggesting that turtles use adaptive ecological niches. Lastly, our results suggest there may be a correlation between diversity of feeding strategy and demography.

Our findings showed that the four islands of Fogo, Maio, Santo Antão and São Vicente support two groups of turtles that diverge in their $\delta^{15} \mathrm{~N}$ values. Despite some variation, these two groups had $\delta^{13} \mathrm{C}$ lower than $-14 \%$, which shows that both groups are formed of oceanic feeders when using previously established criteria for this population (Eder et al. 2012; Pinela et al. 2010, Cardona et al. 2017). The large variation in $\delta^{15} \mathrm{~N}$ seen among individuals nesting in the archipelago $(\sim 15 \%$ o) is unlikely to represent variation in trophic position, as such a variation would cover over four different trophic levels using a typical trophic enrichment factor of 3.4\% (Post 2002) - an improbable scenario for turtles. Instead, this reflects baseline variation in $\delta^{15} \mathrm{~N}$ across the vast oceanic area utilised by Cape Verde turtles who, during their foraging time, remain in the open water between Cape Verde and the African continent, covering $\sim 177,325 \mathrm{~km}^{2}$ (Pikesley et al. 2015). Localised oceanic upwelling in part of this area (Hood et al. 2004; Prange and Schulz 2004) results in consumers incorporating a ${ }^{15} \mathrm{~N}$-enriched label in their tissues (Bergman et al. 2013). Conversely, most pelagic habitats in the region are largely unaffected by upwelling, and turtles feeding in these areas are relatively ${ }^{15} \mathrm{~N}$ depleted compared to their counterparts feeding in upwelling zones.

Differences in $\delta^{15} \mathrm{~N}$ across feeding grounds have been observed in other loggerhead turtle rookeries (the Pacific and Northwest Atlantic), other sea turtle species such as the leatherback (Seminoff et al. 2012; Tucker et al. 2014; Wallace et al. 2006) and even other marine species such as Atlantic bluefin tuna (Thunnus thynnus, Estrada et al. 2005) and humpback whales (Megaptera novaeangliae, Witteveen et al. 2009). Like in our study, $\delta^{15} \mathrm{~N}$ fluctuations in plankton have been linked to upwelling activity in the Eastern Atlantic (Montoya et al. 2002). Average nitrogen fixation rates are up to seven times higher in the surface waters of the upwelling region of the Eastern Equatorial Atlantic because of blooms of non-diazotrophic phytoplankton (Christian and Murtugudde 2003; Subramaniam et al. 2013). Subsequently, this can cause enrichment of ${ }^{15} \mathrm{~N}$ in organisms feeding at higher trophic positions such as sea turtles (Bergman et al. 2013; Goebel et al. 2010; Montoya et al. 2002).

Our data indicate that turtles nesting on Boavista island belong to three isotopic clusters. There, these isotopic clusters differ from one another for both their $\delta^{15} \mathrm{~N}$ and $\delta^{13} \mathrm{C}$ values. The distinct locations in $\delta^{15} \mathrm{~N}-\delta^{13} \mathrm{C}$ isotope space reveal the presence of the two separate oceanic clusters, seen in the 

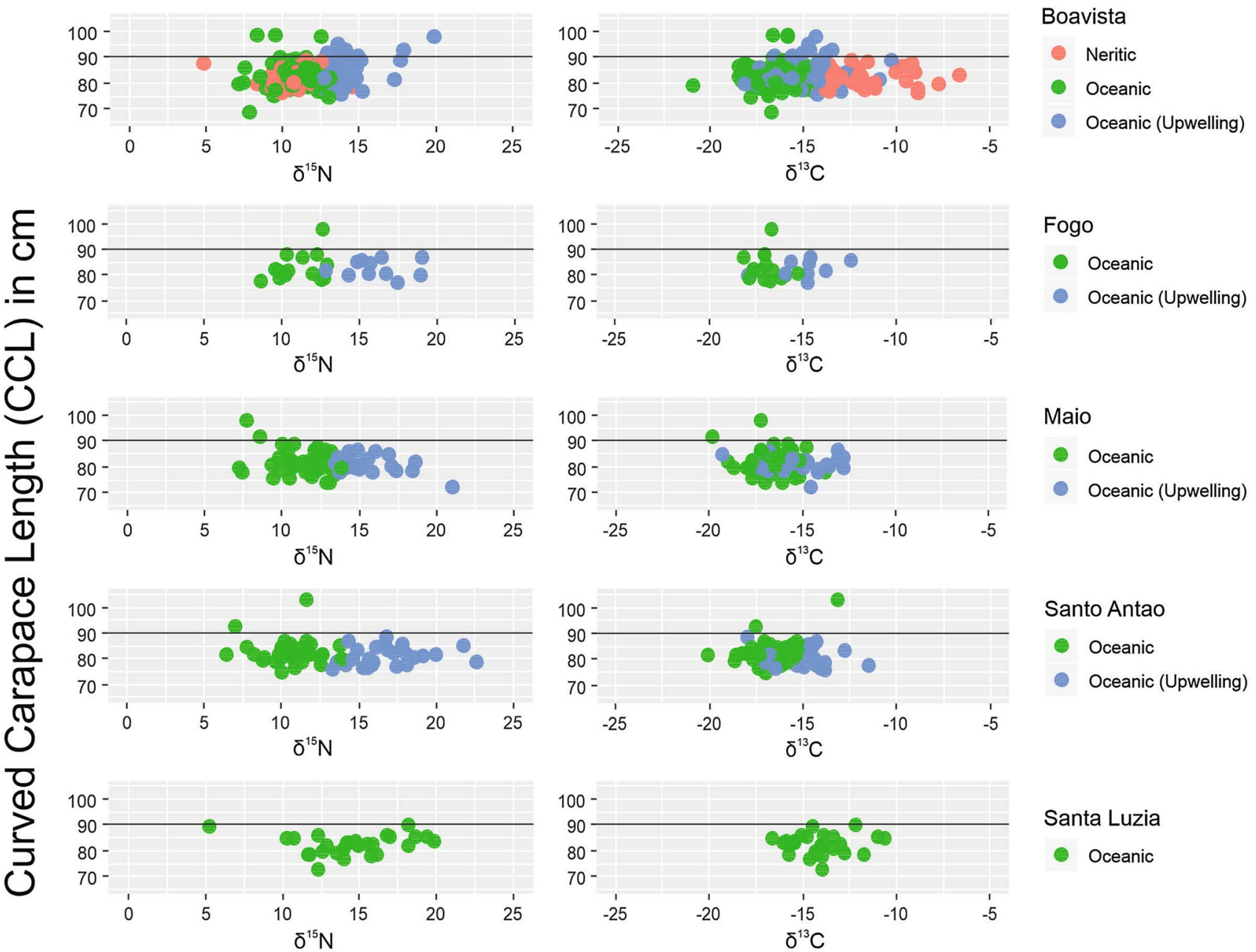

\section{Santo Antao \\ - Oceanic \\ Oceanic (Upwelling)}
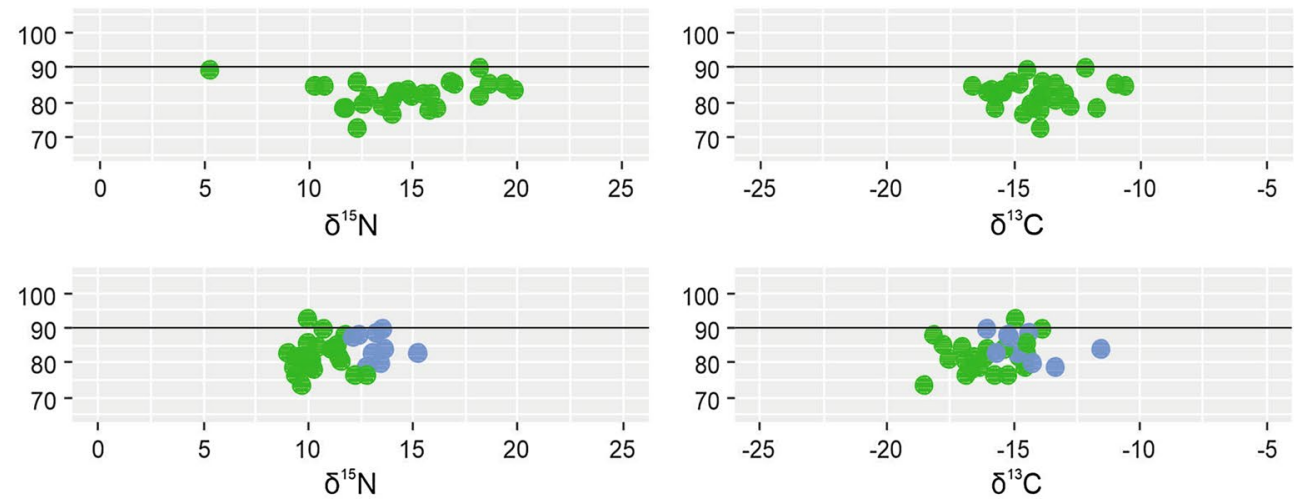

\section{Santa Luzia \\ - Oceanic}

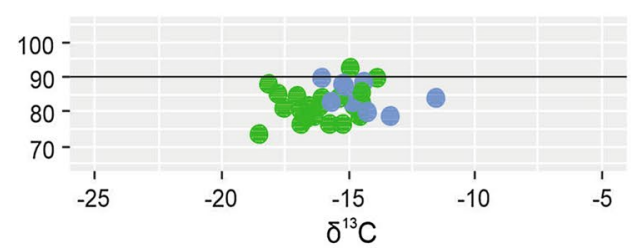

\section{Sao Vicente \\ - Oceanic \\ Oceanic (Upwelling)}

Fig. 3 Scatterplots illustrating the relationship between stable isotopes $\delta^{15} \mathrm{~N}$ and $\delta^{13} \mathrm{C}(\% \circ)$ and the size range of turtles for each affinity propagated isotopic cluster on each island. The black line on each plot

other islands, in addition to a third cluster where turtles show more ${ }^{13} \mathrm{C}$-enriched values. This third cluster likely represents individuals utilising a more neritic habitat and more benthic feeding strategy (Cardona et al. 2017; Eder et al. 2012; Hawkes et al. 2006). Turtles from this group are most likely those described, using satellite telemetry, to feed around the coasts of Sierra Leone (Hawkes et al. 2006; Pikesley et al. 2015). Far fewer turtles were reported to make the journey to this neritic ground than the oceanic $(12.5 \%$ neritic vs. $87.5 \%$ oceanic-Eder et al. 2012; Table 2) and neritic feeders utilise a small range ( $500 \mathrm{~km}^{2}$-Pikesley et al. 2015$)$, consistent with the reduced observed $\delta{ }^{15} \mathrm{~N}$ isotopic variation represents the $90 \mathrm{~cm}$ cutoff between neritic $(>90 \mathrm{~cm})$ and oceanic $(<90 \mathrm{~cm})$ size categories

seen in this group compared to the oceanic groups. We interpret individuals within these different clusters to differ in their feeding strategies, either differing in both their feeding locations and their prey items (i.e., neritic-oceanic) or only their feeding locations (oceanic-oceanic upwelling).

Variation in the number of feeding clusters among nesting groups raises questions about the factors driving such apparent trophic diversity. In Cape Verde, the highest nesting density occurs on Boavista (Marco et al. 2012), followed by the island of Sal (not sampled here), Maio and then the western set of northern and southern islands. While the most distant islands away from Boavista support smaller nesting groups, 
Table 2 Comparison of the 'neritic-oceanic' foraging dichotomy of adult female Caretta caretta circumglobally. Adapted from Eder et al. (2012)

\begin{tabular}{|c|c|c|c|c|c|}
\hline \multirow[t]{2}{*}{ Nesting location } & \multirow[t]{2}{*}{$N$} & \multicolumn{2}{|c|}{ Foraging dichotomy $(\%)(\mathrm{CCL}, \mathrm{cm})$} & \multirow[t]{2}{*}{ Method } & \multirow[t]{2}{*}{ Source } \\
\hline & & Neritic foragers & Oceanic foragers & & \\
\hline \multicolumn{6}{|l|}{ Mediterranean } \\
\hline Greece & 69 & 100 & 0 & ST and SIA & Zbinden et al. (2011) \\
\hline \multicolumn{6}{|l|}{ Pacific Ocean } \\
\hline Japan & 102 & $74[94.0 \pm 4.0]$ & $24[78.4 \pm 3.1]$ & SIA & Hatase et al. (2010) \\
\hline \multicolumn{6}{|l|}{ North Atlantic } \\
\hline North Carolina & 12 & 100 & 0 & ST & Hawkes et al. (2007) \\
\hline Florida & 310 & $46[100.5 \pm 5.5]$ & $54[97.5 \pm 6.0]$ & SIA & Reich et al. (2010) \\
\hline Boavista & 9 & $33[>93.0]$ & $67[<85.5]$ & ST & Hawkes et al. (2006) \\
\hline Boavista & 72 & $12.50[93.1 \pm 5.3]$ & $87.50[82.5 \pm 4.6]$ & SIA and CCL & Eder et al. (2012) \\
\hline Boavista & 202 & $22.28[45]$ & $77.72[157]$ & $\mathrm{AP}$ & Present study \\
\hline Cape Verde & 419 & $18.62[78]$ & $81.38[341]$ & $\mathrm{AP}$ & Present Study \\
\hline \multicolumn{6}{|l|}{ Indian Ocean } \\
\hline Sultanate of Oman & 10 & 20 & 80 & ST & Rees et al. (2010) \\
\hline
\end{tabular}

$N$ number of females studied, $C C L$ curved carapace length $(\mathrm{cm}), S T$ satellite telemetry, SIA stable isotope analysis, $A P$ affinity propagation analysis it was demonstrated that those groups harbour unique genetic diversity, which are identified as a conservation priority (Stiebens et al. 2013a). Here, we found that the turtles from Boavista have a significant negative Tajima's $D$ value, suggestive of population expansion after a bottleneck event, supported by a significant $R_{2}$. Our results further suggest a match between population expansion and increased diversity of feeding strategies, linking large population size with increased trait diversity. Noteworthy, our hypothesis that links demography and trait diversity must be treated with the necessary caution, because the occurrence of rare feeding strategies in smaller populations might be overlooked despite exhaustive sampling. As a precautionary conservation measure, however, we encourage increased protection in islands with small nesting groups. With this study, we do not suggest that the control region of the mtDNA mediates variation of feeding strategies and we cannot exclude this proxy to be correlated with any other genetically coded trait. Here, we imply that mtDNA of the sampled females describes the population history of the nesting groups. Future studies may focus on association mapping using more complete genomic information and may provide further insights into the evolution of feeding strategies whether linked to adaptive diversity or better resolution of demography.

Alternatively, the feeding strategy followed by individual turtles from the Cape Verde archipelago likely reflects some environmental determinism. A new paradigm was proposed where upon natal dispersion linked to ocean currents, hatchlings imprint on feeding grounds, allowing them to return to these grounds as adults (Hays et al. 2010). Hence, under this alternative hypothesis, we suggest that the majority of Cape Verde islands are exposed to ocean currents that propel hatchlings ultimately towards oceanic habitats. Because the nesting density on Boavista is high and consequently the nesting season long, there are likely climatic/oceanic conditions (e.g., Monzón-Argüello et al. 2012) that will propel hatchlings towards the neritic habitats. The smaller nesting groups in the West may be less likely to be exposed to those conditions because of their geographic location and shorter nesting period as a result of reduced population size. This would explain why turtles from Boavista island showed an additional neritic feeding strategy compared to the rest of the nesting groups we sampled. Because turtles are mostly faithful to their natal island and evolve local adaptation under philopatry (Stiebens et al. 2013a), this would explain why variation in feeding strategies also appears to be island specific. Overall, independently of the relative contribution of the genetic and environmental determinisms of feeding ecology, conservation efforts should not neglect turtles from any of the nesting groups to guarantee long-term maintenance of behavioural and trait diversities.

Adult female loggerhead turtles from Cape Verde were thought to utilise both productive neritic habitats and putatively suboptimal oceanic habitats due to variable sizes of observed individuals (Eder et al. 2012; Hawkes et al. 2006). Evidence for the multiple oceanic feeding groups shown in this study existed in a previous study focusing solely on Boavista. Eder et al. (2012) actually referred to group 2a and $2 \mathrm{~b}$ within their oceanic groups, however, sample size likely prevented the statistical detection of two distinct groups. By drastically increasing sample size in our study, and using a non-biased clustering approach, we show that oceanic turtles that feed in a ${ }^{15} \mathrm{~N}$-enriched environment are larger than their counterparts from both other clusters. Hence, oceanic turtles may not actually be utilising suboptimal habitats, but the presence of variable oceanic conditions and the existence 
of upwelling may have driven the evolution of this feeding strategy, explaining the increased abundance of oceanic turtles in the Cape Verde rookery compared to other locations (Table 2). Consequently, this suggests that turtle size cannot be considered a universal indicator of habitat use in Cape Verde. This is contrary to results reported from other rookeries such as the Japanese Rookery (Hatase et al. 2007, 2013), the Northeast Atlantic Rookery (Eder et al. 2012) or the Northwest Atlantic Rookery (McClellan et al. 2010; Reich et al. 2010, Table 2). Noteworthy, there is no correlation between CCL and $\delta^{15} \mathrm{~N}$ of loggerhead turtles from the Mediterranean Sea (Zbinden et al. 2011) or Florida (Mansfield et al. 2009), where there is substantial overlap in the sizes of two groups distinguished by $\delta^{13} \mathrm{C}$ value (Reich et al. 2010), further suggesting that the correlation between turtle size and feeding ecology is rookery specific.

From a conservation perspective, studies on feeding ecology of endangered species are important, as they allow the indirect identification of habitats that need particular protection. Here, the protection of feeding grounds off the coast of Sierra Leone necessitates local and international efforts similar to those habitats exposed to the upwelling events where fishing rates and turtle bycatch are important. At the local scale of Cape Verde, the different size-feeding ecology relationships are likely associated with the evolution of nesting group-specific traits, matching the rather independent functioning of the nesting groups in Cape Verde (Stiebens et al. 2013a). This strongly supports the perspective that functional trait diversity and demography should not be interpreted as independent of one another.

Acknowledgements The authors thank Turtle Foundation particularly Euclides Resende, Joana Nicolau, Chrisitan Roder and Hiltrud Cordes. We would also like to thank Silvana Roque (Projecto Vito Porto Novo), Herculano Diniz (Projecto Vito Fogo), Patricia Rocha and Tommy Melo (BiosferaI) who facilitated the sample collection. The authors also would like to thank two anonymous reviewers and Dr. Joost Raeymaekers for constructive comments which improved the conclusions of this work. The study was supported by a National Geographic grant (GEFNE69-13) and Queen Mary University Funds allocated to CE. CH is supported by Nucleo Milenio INVASAL funded by Chile's government program, Iniciativa Cientifica Milenio from Ministerio de Economia, Fomento y Turismo.

Author contributions SJKC, VAS and CE conceived the study; CE obtained funding; SJKC, VAS, TR, SMC and CE carried out the data collection; SJKC, CH, MB-S and CE performed the analyses; and SJKC, $\mathrm{CH}$ and $\mathrm{CE}$ drafted the manuscript. All authors contributed to the final version and gave final approval for publication.

\section{Compliance with ethical standards}

Conflict of interest All authors declare that they have no conflict of interests.

Ethical approval All applicable institutional and/or national guidelines for the care and use of animal were followed. The work was performed under DGA legislation of Cape Verde (authorizations DGA 30/13, 040/ GP/INDP/14).

Open Access This article is distributed under the terms of the Creative Commons Attribution 4.0 International License (http://creativeco mmons.org/licenses/by/4.0/), which permits unrestricted use, distribution, and reproduction in any medium, provided you give appropriate credit to the original author(s) and the source, provide a link to the Creative Commons license, and indicate if changes were made.

\section{References}

Abzhanov A, Protas M, Grant BR, Grant PR, Tabin CJ (2004) Bmp4 and morphological variation of beaks in Darwin's Finches. Science 305:1462-1465

Albertson RC, Streelman JT, Kocher TD, Yelick PC (2005) Integration and evolution of the cichlid mandible: the molecular basis of alternate feeding strategies. Proc Natl Acad Sci USA 102:16287-16292

Bandelt HJ, Forster P, Rohl A (1999) Median-joining networks for inferring intraspecific phylogenies. Mol Biol Evol 16:37-48

Bergman B, Sandh G, Lin S, Larsson J, Carpenter EJ (2013) Trichodesmium-a widespread marine cyanobacterium with unusual nitrogen fixation properties. FEMS Microbiol Rev 37:286-302

Bodenhofer U, Kothmeier A, Hochreiter S (2011) APCluster: an R package for affinity propagation clustering. Bioinformatics 27:2463-2464

Bolten AB, Witherington BE (2003) Loggerhead sea turtles. Smithsonian Books, Washington, DC

Börger L, Dalziel BD, Fryxell JM (2008) Are there general mechanisms of animal home range behaviour? A review and prospects for future research. Ecol Lett 11:637-650

Cardona L, Martins S, Uterga R, Marco A (2017) Individual specialization and behavioral plasticity in a long-lived marine predator. $\mathrm{J}$ Exp Mar Biol Ecol 497:127-133

Christian JR, Murtugudde R (2003) Tropical Atlantic variability in a coupled physical-biogeochemical ocean model. Deep-Sea Res Part II Top Stud Oceanogr 50:2947-2969

Dodd CK (1988) Synopsis of the biological data on the loggerhead sea turtle Caretta caretta (Linnaeus 1758). DTIC Document

Eder E, Ceballos A, Martins S, Perez-Garcia H, Marin I, Marco A, Cardona L (2012) Foraging dichotomy in loggerhead sea turtles Caretta caretta off northwestern Africa. Mar Ecol Prog Ser 470:113-122

Edgar RC (2004) MUSCLE: a multiple sequence alignment method with reduced time and space complexity. BMC Bioinform 5:113

Eizaguirre C, Baltazar-Soares M (2014) Evolutionary conservationevaluating the adaptive potential of species. Evol Appl 7:963-967

Estrada JA, Lutcavage M, Thorrold SR (2005) Diet and trophic position of Atlantic bluefin tuna (Thunnus thynnus) inferred from stable carbon and nitrogen isotope analysis. Mar Biol 147:37-45

Excoffier L, Lischer HE (2010) Arlequin suite ver 3.5: a new series of programs to perform population genetics analyses under Linux and Windows. Mol Ecol Resour 10(3):564-567

Frick MG, Williams KL, Bolten AB, Bjorndal KA, Martins HR (2009) Foraging ecology of oceanic-stage loggerhead turtles Caretta caretta. Endanger Species Res 9:91-97

Fu Y-X (1997) Statistical tests of neutrality of mutations against population growth, hitchhiking and background selection. Genetics 147:915-925 
Godley B, Blumenthal J, Broderick A, Coyne M, Godfrey M, Hawkes L, Witt M (2008) Satellite tracking of sea turtles: where have we been and where do we go next? Endanger Species Res 4:3-22

Goebel NL, Turk KA, Achilles KM, Paerl R, Hewson I, Morrison AE, Montoya JP, Edwards CA, Zehr JP (2010) Abundance and distribution of major groups of diazotrophic cyanobacteria and their potential contribution to $\mathrm{N}_{2}$ fixation in the tropical Atlantic Ocean. Environ Microbiol 12:3272-3289

Harpending HC (1994) Signature of ancient population growth in a low-resolution mitochondrial DNA mismatch distribution. Hum Biol 66:591-600

Harpending HC, Sherry ST, Rogers AR, Stoneking M (1993) The genetic structure of ancient human populations. Curr Anthropol 34:483-496

Hatase H, Tsukamoto K (2008) Smaller longer, larger shorter: energy budget calculations explain intrapopulation variation in remigration intervals for loggerhead sea turtles (Caretta caretta). Can J Zool 86:595-600

Hatase H, Takai N, Matsuzawa Y, Sakamoto W, Omuta K, Goto K, Arai N, Fujiwara T (2002) Size-related differences in feeding habitat use of adult female loggerhead turtles Caretta caretta around Japan determined by stable isotope analyses and satellite telemetry. Mar Ecol Prog Ser 233:273-281

Hatase H, Omuta K, Tsukamoto K (2007) Bottom or midwater: alternative foraging behaviours in adult female loggerhead sea turtles. J Zool 273:46-55

Hatase H, Omuta K, Tsukamoto K (2010) Oceanic residents, neritic migrants: a possible mechanism underlying foraging dichotomy in adult female loggerhead turtles (Caretta caretta). Mar Biol 157:1337-1342

Hatase H, Omuta K, Tsukamoto K (2013) A mechanism that maintains alternative life histories in a loggerhead sea turtle population. Ecology 94:2583-2594

Hawkes LA, Broderick AC, Coyne MS, Godfrey MH, Lopez-Jurado LF, Lopez-Suarez P, Merino SE, Varo-Cruz N, Godley BJ (2006) Phenotypically linked dichotomy in sea turtle foraging requires multiple conservation approaches. Curr Biol 16:990-995

Hawkes LA, Broderick AC, Coyne MS, Godfrey MH, Godley BJ (2007) Only some like it hot - quantifying the environmental niche of the loggerhead sea turtle. Divers Distrib 13(4):447-457

Hawkes LA, Witt MJ, Broderick AC, Coker JW, Coyne MS, Dodd M, Frick MG, Godfrey MH, Griffin DB, Murphy SR (2011) Home on the range: spatial ecology of loggerhead turtles in Atlantic waters of the USA. Divers Distrib 17:624-640

Hays GC, Fossette S, Katselidis KA, Mariani P, Schofield G (2010) Ontogenetic development of migration: Lagrangian drift trajectories suggest a new paradigm for sea turtles. J R Soc Interface 7:1319-1327

Hobson KA (1999) Tracing origins and migration of wildlife using stable isotopes: a review. Oecologia 120:314-326

Hood RR, Coles VJ, Capone DG (2004) Modeling the distribution of Trichodesmium and nitrogen fixation in the Atlantic Ocean. J Geophys Res Oceans 109:C6

Hopkins-Murphy S, Owens D, Murphy T (2003) Ecology of immature loggerheads on foraging grounds and adults in internesting habitat in the eastern United States. Loggerhead Sea Turtles 1:79-92

Isaac NJ, Cowlishaw G (2004) How species respond to multiple extinction threats. Proc R Soc Lond B 271:1135-1141

IUCN (2016) The IUCN red list of threatened species. Caretta caretta, www.iucnredlist.org. Accessed 14 Dec 2016

Le Galliard JF, Clobert J, Ferrière R (2004) Physical performance and Darwinian fitness in lizards. Nature 432:502-505

López-Jurado L, Varo-Cruz N, López-Suárez P (2003) Incidental capture of loggerhead turtles (Caretta caretta) on Boa Vista (Cape Verde Islands). Mar Turt Newsl 101:14-16
Mansfield KL, Saba VS, Keinath JA, Musick JA (2009) Satellite tracking reveals a dichotomy in migration strategies among juvenile loggerhead turtles in the Northwest Atlantic. Mar Biol 156:2555-2570

Marco A, Abella E, Liria-Loza A, Martins S, López O, Jiménez-Bordón S, Medina M, Oujo C, Gaona P, Godley B (2012) Abundance and exploitation of loggerhead turtles nesting in Boa Vista island, Cape Verde: the only substantial rookery in the eastern Atlantic. Anim Conserv 15:351-360

McClellan CM, Read AJ (2007) Complexity and variation in loggerhead sea turtle life history. Biol Lett 3:592-594

McClellan CM, Braun-McNeill J, Avens L, Wallace BP, Read AJ (2010) Stable isotopes confirm a foraging dichotomy in juvenile loggerhead sea turtles. J Exp Mar Biol Ecol 387:44-51

Montoya JP, Carpenter EJ, Capone DG (2002) Nitrogen fixation and nitrogen isotope abundances in zooplankton of the oligotrophic North Atlantic. Limnol Oceanogr 47:1617-1628

Monzón-Argüello C, Rico C, Naro-Maciel E, Varo-Cruz N, López P, Marco A, López-Jurado LF (2010) Population structure and conservation implications for the loggerhead sea turtle of the Cape Verde Islands. Conserv Genet 11:1871-1884

Monzón-Argüello C, Dell'Amico F, Morinière P, Marco A, LópezJurado LF, Hays GC, Scott R, Marsh R, Lee PLM (2012) Lost at sea: genetic, oceanographic and meteorological evidence for storm-forced dispersal. J R Soc Interface 9:1725-1732

Myers N, Mittermeier RA, Mittermeier CG, Da Fonseca GA, Kent J (2000) Biodiversity hotspots for conservation priorities. Nature 403:853-858

Pikesley SK, Broderick AC, Cejudo D, Coyne MS, Godfrey MH, Godley BJ, Lopez P, López-Jurado LF, Elsy Merino S, Varo-Cruz N (2015) Modelling the niche for a marine vertebrate: a case study incorporating behavioural plasticity, proximate threats and climate change. Ecography 38:803-812

Pimm SL, Jenkins CN, Abell R, Brooks TM, Gittleman JL, Joppa LN, Raven PH, Roberts CM, Sexton JO (2014) The biodiversity of species and their rates of extinction, distribution, and protection. Science 344:1246752

Pinela A, Borrell A, Cardona L, Aguilar A (2010) Stable isotope analysis reveals habitat partitioning among marine mammals off the NW African coast and unique trophic niches for two globally threatened species. Mar Ecol Prog Ser 416:295-306

Plotkin P (2003) Adult migrations and habitat use. Biol Sea Turtles 2:225-241

Polzin T, Daneschmand SV (2003) On Steiner trees and minimum spanning trees in hypergraphs. Oper Res Lett 31:12-20

Post DM (2002) Using stable isotopes to estimate trophic position: models, methods, and assumptions. Ecology 83:703-718

Prange M, Schulz M (2004) A coastal upwelling seesaw in the Atlantic Ocean as a result of the closure of the Central American Seaway. Geophys Res Lett. https://doi.org/10.1029/2004GL020073

Ramos-Onsins SE, Rozas J (2002) Statistical properties of new neutrality tests against population growth. Mol Biol Evol 19:2092-2100

Rees AF, Al Saady S, Broderick AC, Coyne MS, Papathanasopoulou N, Godley BJ (2010) Behavioural polymorphism in one of the world's largest populations of loggerhead sea turtles Caretta caretta. Mar Ecol Prog Ser 418:201-212

Reich KJ, Bjorndal KA, Bolten AB (2007) The 'lost years' of green turtles: using stable isotopes to study cryptic lifestages. Biol Let 3:712-714

Reich KJ, Bjorndal KA, Frick MG, Witherington BE, Johnson C, Bolten AB (2010) Polymodal foraging in adult female loggerheads (Caretta caretta). Mar Biol 157:113-121

Rozas J, Librado PJR (2009) DnaSP v5: a software for comprehensive analysis of DNA polymorphism data. Bioinformatics 25(11):1451-1452 
Seminoff JA, Benson SR, Arthur KE, Eguchi T, Dutton PH, Tapilatu RF, Popp BN (2012) Stable isotope tracking of endangered sea turtles: validation with satellite telemetry and $\delta 15 \mathrm{~N}$ analysis of amino acids. PLoS One 7:e37403

Shamblin BM, Bolten AB, Abreu-Grobois FA, Bjorndal KA, Cardona L, Carrera C, Clusa C, Monzon-Arguello C, Nairn CJ, Nielsen JT, Nel R, Soares LS, Stewart KR, Vilaca ST, Türko-zan O, Yilmaz C, Dutton PH (2014) Geographic patterns of genetic variation in a broadly distributed marine vertebrate: new insights into loggerhead turtle stock structure from expanded mitochondrial DNA sequences. PLoS One 9(1):e85956

Sims DW, Southall EJ, Humphries NE, Hays GC, Bradshaw CJ, Pitchford JW, James A, Ahmed MZ, Brierley AS, Hindell MA (2008) Scaling laws of marine predator search behaviour. Nature 451:1098-1102

Smith JM, Price GR (1973) The logic of animal conflict. Nature 246(5427):15-18

Stearns SC (1992) The evolution of life histories. Oxford University Press, Oxford

Stephens DW, Krebs JR (1986) Foraging theory. Princeton University Press, Oxford

Stiebens VA, Merino SE, Roder C, Chain FJ, Lee PL, Eizaguirre C (2013a) Living on the edge: how philopatry maintains adaptive potential. Proc R Soc Lond B Biol Sci 280:20130305

Stiebens VA, Merino SE, Chain FJ, Eizaguirre C (2013b) Evolution of MHC class I genes in the endangered loggerhead sea turtle (Caretta caretta) revealed by 454 amplicon sequencing. BMC Evol Biol 13:95

Subramaniam A, Mahaffey C, Johns W, Mahowald N (2013) Equatorial upwelling enhances nitrogen fixation in the Atlantic Ocean. Geophys Res Lett 40:1766-1771

Taylor H, Cozens J (2010) The effects of tourism, beachfront development and increased light pollution on nesting loggerhead turtles Caretta caretta (Linnaeus, 1758) on Sal, Cape Verde Islands
Thomson JA, Heithaus MR, Burkholder DA, Vaudo JJ, Wirsing AJ, Dill LM (2012) Site specialists, diet generalists? Isotopic variation, site fidelity, and foraging by loggerhead turtles in Shark Bay, Western Australia. Mar Ecol Prog Ser 453:84-96

Tucker AD, MacDonald BD, Seminoff JA (2014) Foraging site fidelity and stable isotope values of loggerhead turtles tracked in the Gulf of Mexico and Northwest Caribbean. Mar Ecol Prog Ser 502:267-279

Wallace BP, Seminoff JA, Kilham SS, Spotila JR, Dutton PH (2006) Leatherback turtles as oceanographic indicators: stable isotope analyses reveal a trophic dichotomy between ocean basins. Mar Biol 149:953-960

Wallace BP, Avens L, Braun-McNeill J, McClellan CM (2009) The diet composition of immature loggerheads: insights on trophic niche, growth rates, and fisheries interactions. J Exp Mar Biol Ecol 373:50-57

Witteveen BH, Worthy GA, Wynne KM, Roth JD (2009) Population structure of North Pacific humpback whales on their feeding grounds revealed by stable carbon and nitrogen isotope ratios. Mar Ecol Prog Ser 379:299-310

Zbinden JA, Bearhop S, Bradshaw P, Gill B, Margaritoulis D, Newton J, Godley BJ (2011) Migratory dichotomy and associated phenotypic variation in marine turtles revealed by satellite tracking and stable isotope analysis. Mar Ecol Prog Ser 421:291-302

Publisher's Note Springer Nature remains neutral with regard to jurisdictional claims in published maps and institutional affiliations. 